\title{
A química no ensino médio tendo "detergente" como tema motivador
}

\section{Chemistry in high school having the 'detergent' as a motivating theme}

\author{
Olívio Fernandes Galão ${ }^{1}$; Eliana Aparecida Silicz Bueno ${ }^{1}$; Dionisio Borsato ${ }^{1}$; \\ Flaveli Aparecida de Souza Almeida ${ }^{1}$; Ivanira Moreira ${ }^{1}$; Antonio Martins ${ }^{2}$
}

\section{Resumo}

O presente trabalho teve como objetivo associar o ensino de alguns conceitos de química com o cotidiano dos alunos do Ensino Médio. O tema escolhido foi "detergente" porque este produto faz parte da vida diária das pessoas já há algumas décadas. Devido à presença de agente tensoativo, fosfatos e outras substâncias em sua composição, este produto tem provocado problemas ao ambiente. Partindo do tema motivador "detergente" e com a elaboração de um mapa conceitual foi possível abordar conceitos de ligações de hidrogênio, tensão superficial, forças de van der Waals, solubilidade, e ainda a questão da biodegradabilidade de produtos químicos no ambiente.

Palavras-chave: Detergente, Tensoativo, Biodegradabilidade, Mapa Conceitual.

\begin{abstract}
The present work was developed with the objective of associating the teaching of some concepts of chemistry with the daily routine of High School students. The chosen subject was "detergents" because this product has taken part in the daily lives of people for some years now. Due to the presence of a tensor active agent, phosphates and other substances in their composition, these products have caused some damage to the environment. Starting by the motivating topic "detergents" and with the building of a conceptual map, it was possible to cover the concepts of hydrogen bonds, surface tension, van der Waals bonds, solubility and also the question of biodegradability of chemical products in the environment. Key Words: detergents, tensor active agent, biodegradability, conceptual map.
\end{abstract}

\section{Introdução}

O compromisso com a melhoria do processo de ensino e aprendizagem em Química justifica a necessidade do professor utilizar diferentes estratégias pedagógicas, uma vez que este processo acontece com a sua prática em sala de aula. Uma forma de abordagem de conceitos químicos, no Ensino Médio, é através da construção e uso de mapas conceituais, que é um modelo que mostra as relações significativas entre os conceitos mais importantes, tendo um determinado assunto como tema central (NOVAK, 1988). O mapa conceitual é

\footnotetext{
1 Departamento de Química da Universidade Estadual de Londrina. Cx.P. 6001, CEP 86051-990, Londrina-PR.

2 Colégio Estadual Souza Naves, Rolândia-PR.
} 
um instrumento capaz de evidenciar significados atribuídos a conceitos e suas relações no contexto de um determinado conhecimento ou assunto.

O tema motivador escolhido foi "Detergente", e os tópicos abordados no ensino de química a partir do tema motivador proposto foram os conceitos de tensão superficial, ligação hidrogênio, forças de van der Waals e disposição dos átomos nas cadeias carbônicas. Estes conceitos estão relacionados com as propriedades dos agentes surfatantes, como solubilidade em água, formação de micelas, poder detergente, biodegradabilidade, poder espumante e interações químicas, e fazem parte do cotidiano dos alunos.

Os surfatantes dos sabões e dos detergentes sintéticos são os princípios ativos que efetuam na lavagem a ação de limpeza primária e de espumejamento, mediante o mecanismo de redução da tensão superficial (SHREVE ; BRINK, 1997). A performance de um detergente se verifica por aspectos como: capacidade detergente, formação e estabilidade da espuma, viscosidade e suavidade à pele. A tecnologia de formulação mais empregada no Brasil combina tensoativos aniônicos agindo como detergentes; tensoativos não-iônicos atuando como estabilizadores de espuma e espessantes; reforçadores e diversos aditivos conforme o fim a que se destina (BORSATO; GALÃO; MOREIRA, 1999). Os sabões e detergentes sintéticos praticamente não sofrem modificações químicas nos processos de lavagem com água (salvo formações de sais de cálcio, magnésio e outros, quando se usam as chamadas águas duras) e encontram-se, portanto, presentes nas águas residuais de escoamento das operações de lavagem, incorporando-se ao esgoto doméstico (MARTINS, 1998). Por natureza química, os sabões feitos de matérias graxas são totalmente biodegradáveis e quase não interferem com a fauna e flora aquática, não possibilitando a formação de espumas. Os produtos formulados a partir de ingredientes ativos do tipo aniônico como os sais de sódio de alquilbenzeno sulfonados lineares (LAS) causam o inconveniente de formação acentuada de espumas nos cursos de águas receptoras (BORSATO;
GALÃO; MOREIRA, 1999). Além dos surfatantes, os detergentes podem apresentar na sua composição fosfatos complexos que, na presença de água dura, podem garantir um bom desempenho do agente tensoativo. Porém, podem também originar diversos problemas ecológicos. Esses problemas dizem respeito à eutroficação, ou seja, ao aumento da fertilidade das águas devido aos fosfatos, o que favorece o crescimento excessivo de algas em águas receptoras de efluentes, provocando a redução acentuada do oxigênio dissolvido nas águas. A carga de poluição decorrente da presença desses sabões e detergentes sintéticos é muito pequena se comparada com outros poluentes usualmente presentes no esgoto. Apesar disso, ela pode contribuir de maneira bastante desfavorável para a poluição das águas receptoras e dificultar os procedimentos normais de tratamento de esgotos residuais (FAIRBANKS, 1989).

Com o objetivo de desenvolver alguns conceitos químicos de uma forma contextualizada e utilizando um tema motivador que é do cotidiano do aluno foi trabalhado o tema "detergente".

\section{Material e métodos}

\subsection{Mapa conceitual}

O mapa conceitual tendo como tema motivador "Detergente" (Figura 1) foi elaborado e pode ser utilizado pelo professor para ordenar e seqüenciar os conteúdos a serem trabalhados em sala de aula. Servirá posteriormente como um roteiro e conseqüentemente poderá fornecer um caminho próprio ao professor de acordo com as condições de trabalho, em função das características dos alunos, do número de aulas disponíveis e da escola.

O mapa conceitual (Figura 1) foi aplicado junto aos alunos do ensino médio do Colégio Estadual Souza Naves de Rolândia-PR. Todos os conceitos relacionados no mapa conceitual foram abordados em sala através de aulas expositivas, discussão em grupos e pesquisa bibliográfica, sendo devidamente avaliados. 
O que despertou interesse nos alunos foi a atividade experimental selecionada realizada no laboratório do Colégio e posteriormente complementada nos laboratórios do Departamento de Química da Universidade Estadual de Londrina (UEL). Além disso, os alunos estudaram a composição química dos detergentes e a função de cada componente utilizado na sua formulação.

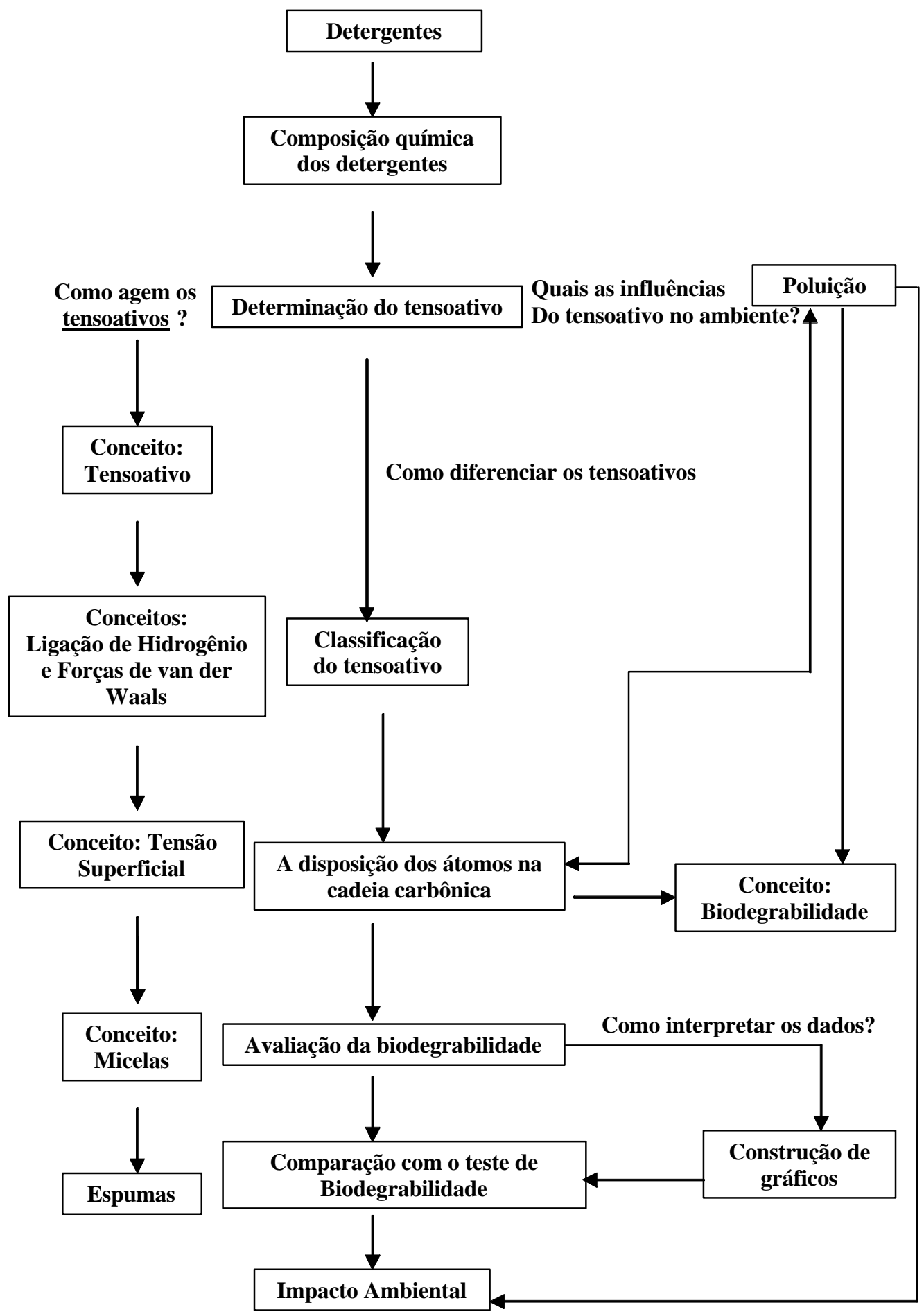

Figura 1 - Mapa conceitual padrão mostrando os principais tópicos e conceitos, sobre detergentes, abordados em sala de aula. 


\subsection{Amostras de detergentes}

Para a análise da matéria ativa aniônica foram utilizadas 6 amostras de marcas diferentes de detergentes líquidos comercializados em Rolândia-PR.

\subsubsection{A determinação da matéria ativa aniônica}

Foi realizada no laboratório do Colégio, em triplicatas, utilizando-se o método do azul de metileno (BORSATO; GALÃO; MOREIRA, 1999). A determinação da umidade foi realizada no laboratório do Departamento de Química da UEL utilizando cadinho de porcelana contendo, aproximadamente, $1 \mathrm{~g}$ de amostra em estufa, numa faixa de temperatura de 100 a $110^{\circ} \mathrm{C}$, até peso constante. Após a determinação da umidade a mesma amostra foi colocada em uma mufla a $600^{\circ} \mathrm{C}$, durante 3 horas, para a determinação do teor de matérias voláteis e cinzas.

\subsection{Avaliação da biodegradabilidade}

\subsubsection{Preparo do inóculo}

Foram pesados $100 \mathrm{~g}$ de solo fértil de jardim (com baixo teor de argila, areia e matéria orgânica), e a ele foi adicionado água destilada em volume necessário para obter $1000 \mathrm{~mL}$. Deixou-se em repouso por 30 minutos (BRASIL, 1998).

Foi filtrado o sobrenadante através de filtro grosso (papel de filtro para café). Desprezaram-se os primeiros $200 \mathrm{~mL}$ e coletou-se o restante. $\mathrm{O}$ filtrado foi mantido em condições aeróbias até o momento do teste. Utilizou-se o inóculo no mesmo dia em que foi preparado (BRASIL, 1998).

\subsubsection{Meio mineral (BRASIL, 1998)}

Foram dissolvidos em $1000 \mathrm{~mL}$ de água destilada e deionizada.

Fosfato monopotássico P. A $0,0085 \mathrm{~g}$

Fosfato dipotássico P. A $0,02175 \mathrm{~g}$
Fosfato dissódico dihidratado P. A. ....... 0,03340g

Cloreto de amônio P. A $0,00170 \mathrm{~g}$

Sulfato de magnésio heptahidratado P.A ... 0,02250g

Cloreto de cálcio P. A $0,02750 \mathrm{~g}$

Cloreto férrico hexahidratado P. A $0,00025 \mathrm{~g}$

2.3.3 Preparo da amostra para o ensaio de avaliação da biodegradabilidade (MARTINS, 1998).

Uma solução contendo $1 \%$ em volume do detergente foi obtida dissolvendo-se $2,5 \mathrm{~mL}$ do detergente comercial com $5 \mathrm{~mL}$ do inóculo. Em seguida, completou-se o volume para $250 \mathrm{~mL}$ com o meio mineral recentemente preparado. Considerando que a avaliação foi do detergente adquirido, o conservante presente nas amostras não foi eliminado.

\subsubsection{Ensaio de avaliação da biodegradabilidade}

Foram colocados $10 \mathrm{~mL}$ da solução da amostra preparada em 2.3.3, em uma proveta graduada de $100 \mathrm{~mL}$ com tampa. O teste de batimento foi realizado agitando-se vigorosamente a proveta graduada no intervalo de um minuto em cada dia do teste. Foi medida, na proveta, a altura da espuma formada (em $\mathrm{mL})$ e registrada diariamente durante 15 dias consecutivos. Com os dados obtidos foi construído o gráfico denominado de avaliação da biodegradabilidade do detergente, plotando-se a altura da espuma (em mL) em função do tempo (em dias).

\subsubsection{Determinação da biodegradabilidade}

A determinação da biodegradabilidade, do princípio ativo de detergente, foi realizada nos laboratórios da UEL seguindo-se o método proposto pela Portaria 393. Este procedimento operacional padronizado estabelece a metodologia a ser adotada para a determinação da biodegradabilidade de tensoativos utilizados na composição de saneantes 
ou tensoativos aniônico puros. O grau de biodegradabilidade é expresso em percentagem e refere-se a substâncias ativas ao azul de metileno que desaparecem sob as condições específicas do ensaio tendo como referência o dodecilbenzeno sulfonato de sódio, testado em paralelo, como critério de verificação da validade do método (BRASIL, 1998).

\section{Resultados}

Os ensaios de determinação do teor de tensoativos aniônicos, nas 6 amostras de detergentes líquidos utilizados, foram executados pelos alunos da disciplina de química ministrada no Colégio Souza Naves de Rolândia-PR. A Tabela 1 apresenta os teores da matéria ativa aniônica, matérias voláteis e resíduos a $600^{\circ} \mathrm{C}$. Os detergentes analisados apresentaram um teor médio de 8,50\% em massa do tensoativo aniônico.

Tabela 1 - Porcentagem de aniônicos, matérias voláteis a $110^{\circ} \mathrm{C}$ e resíduo a $600^{\circ} \mathrm{C}$ de 6 amostras de detergentes comercializados em Rolândia-PR.

\begin{tabular}{c|c|c|c}
\hline Detergente & \% de aniônico & $\begin{array}{c}\text { \% de voláteis a } \\
110^{\circ} \mathrm{C}\end{array}$ & $\begin{array}{c}\% \text { de resíduo a } \\
600^{\circ} \mathrm{C}\end{array}$ \\
\hline A & 7,67 & 89,77 & 2,14 \\
\hline B & 6,72 & 91,68 & 2,45 \\
\hline C & 8,54 & 89,12 & 1,94 \\
\hline D & 8,01 & 89,61 & 2,30 \\
\hline E & 9,65 & 87,23 & 2,31 \\
\hline F & 10,41 & 80,35 & 8,51 \\
\hline
\end{tabular}

$\mathrm{O}$ detergente $\mathrm{F}$ apresentou um teor de resíduo mais elevado, indicando uma maior quantidade de espessantes inorgânicos em sua composição química.

A altura da espuma produzida, no teste de batimento de espuma, depende do teor de agente tensoativo presente na amostra. Portanto, para realizar o ensaio de avaliação da biodegradabilidade utilizamos os detergentes $\mathrm{Ce} \mathrm{D}$, porque apresentaram valores de aniônicos mais próximos da média e também entre si.
A taxa de biodegradação do detergente $\mathrm{D}$, no ensaio de batimento de espuma, foi menor que a do detergente $\mathrm{C}$ devido a presença de maior quantidade de produtos inorgânicos (Tabela 1) e, possivelmente, um teor mais elevado e/ou uso de agente conservante.

A Figura 2 mostra a redução gradativa do teor de tensoativo, representado pela redução da altura da espuma produzida pelo teste de batimento. No início do experimento, a altura da espuma, medida em proveta, para o detergente $\mathrm{C}$ foi de $100 \mathrm{~mL}$ e $85 \mathrm{~mL}$ para o detergente $\mathrm{D}$ devido a maior quantidade de tensoativo na amostra C (Tabela 1). Mesmo com a presença de conservantes, que não foram eliminados das amostras, após 15 dias de ensaios, os resultados mostraram uma redução de aproximadamente $60 \%$ no volume da espuma, para o detergente $\mathrm{D}$ e $65 \%$ para o detergente $\mathrm{C}$, conforme pode ser observado na Figura 2.

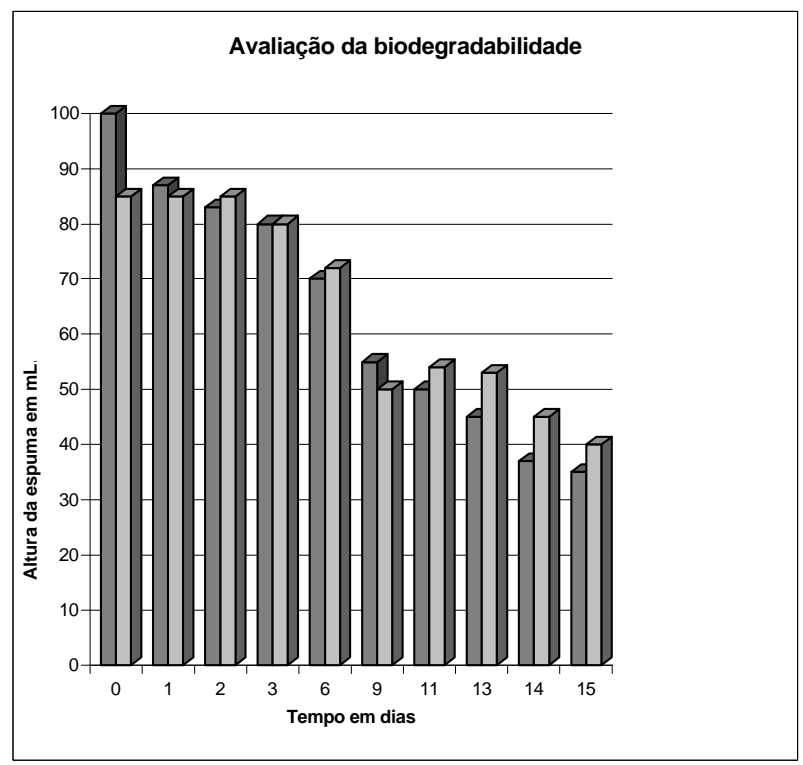

Figura 2 - Avaliação da biodegradabilidade de dois detergentes $(\mathrm{C}$ e $\mathrm{D})$, com matéria ativa aniônica, através do teste de batimento em proveta graduada. Para cada dia indicado a primeira coluna refere-se ao detergente $\mathrm{C}$ e a segunda coluna ao detergente $\mathrm{D}$.

Para efeito de comparação foi realizado, no laboratório do Departamento de Química da UEL, o teste quantitativo de biodegradabilidade de um dos 
detergentes contendo tensoativo aniônico. Para tanto, foi extraído o princípio ativo e realizado o ensaio de biodegradabilidade conforme descrito na Portaria 393 (BRASIL, 1998). O resultado mostrou que restavam apenas $9,0 \%$ do princípio ativo aniônico após 14 dias de ensaio, como podemos observar na Figura 3. De acordo com os padrões estabelecidos pela mesma Portaria, o produto pode ser considerado satisfatório com relação à sua biodegradabilidade, pois o mesmo superou o mínimo estabelecido, que é de $90 \%$, após 14 dias de teste.

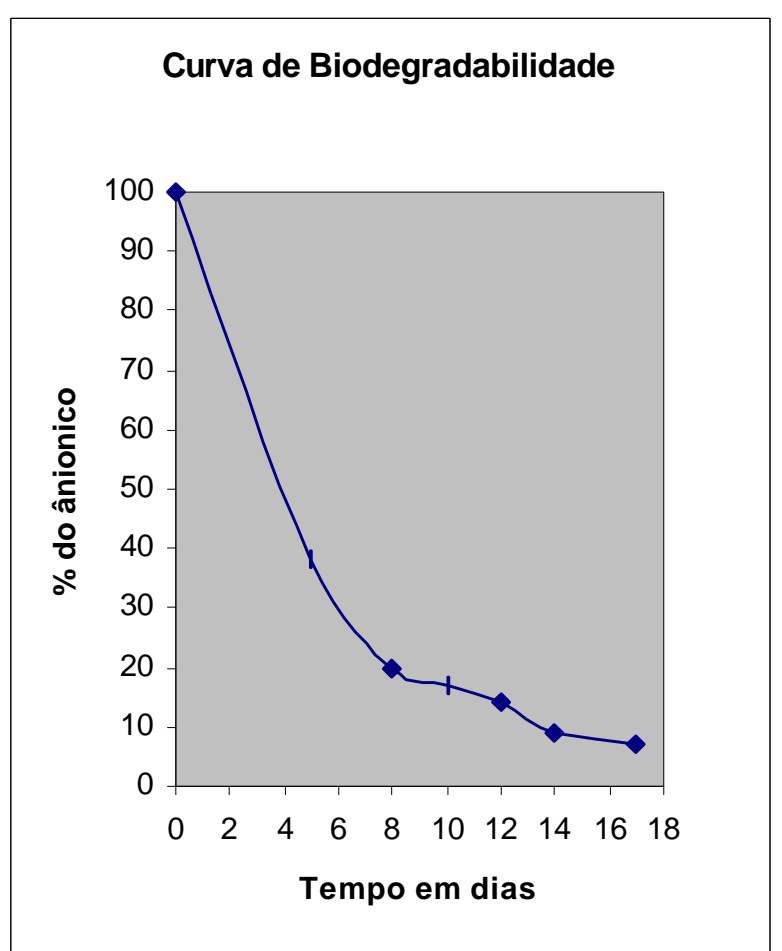

Figura 3 - Curva de biodegradação de um surfatante aniônico mostrando a percentagem do aniônico remanescente em função do tempo em dias.

O teste de batimento de espuma (qualitativo) e o ensaio de biodegradabilidade mostram a degradação do agente tensoativo aniônico, utilizado na formulação dos detergentes, por microrganismos. Em decorrência desse processo são produzidas substâncias consideradas não nocivas ao meio ambiente ou que possuam grau de toxidade inferior ao da substância tensoativa original.

O teste de batimento de espuma, no intervalo de tempo estudado, não teve a redução total da espuma, devido aos componentes inorgânicos e conservantes presentes nos detergentes, que podem interferir na biodegradação do agente surfatante (Tabela 1). Já o ensaio de biodegradabilidade não sofreu esta interferência porque foi efetuado com o tensoativo obtido, do produto comercial, através de extração alcoólica (BRASIL, 1998).

Os valores do teor de tensoativo nos detergentes analisados, o resultado do teste de espuma e o do ensaio de biodegradabilidade foram discutidos e relacionados com os conceitos estudados. A estratégia do uso do mapa conceitual mostrou ser satisfatória para abordagem do tema motivador "detergente".

Ficou evindenciado também a interdisciplinariedade, pois durante o desenvolvimento da atividade os alunos trabalharam com a matemática calculando porcentagem, fazendo conversões de unidades, construindo e interpretando os gráficos da avaliação da biodegradabilidade e da curva de biodegradabilidade.

A avaliação da aprendizagem foi feita através de relatórios, concluindo que o desenvolvimento do trabalho foi eficaz utilizando a estratégia proposta.

Outro fator que demonstra ser positivo o resultado da atividade foi o interesse dos alunos em participarem de Feira de Ciências expondo trabalhos com o tema desenvolvido.

\section{Conclusões}

Os testes de biodegradação são utilizados para prever a velocidade e a extensão da degradação de produtos químicos no meio ambiente. A biodegradabilidade é reconhecida como indicador de segurança ambiental e as condições de testes devem ser as mais próximas das condições reais.

A aplicação de um tema motivador para ensinar conceitos de química se mostrou eficaz, pois com a adoção do assunto "detergente" e a partir do mapa 
conceitual elaborado, foi possível relacionar o ensino de química com o cotidiano. A presença do agente tensoativo nos detergentes possibilitou abordar conceitos relacionados com as forças de van der Waals, tensão superficial, formação de micelas, solubilidade, etc.. A forma como os átomos de carbono estão dispostos na cadeia dão idéia do grau de biodegradabilidade, o que possibilita avaliar o impacto do mesmo sobre o ambiente.

\section{Referências}

BORSATO,D.; GALÃO, O. F.; MOREIRA, I.

Detergentes naturais e sintéticos: um guia técnico. Londrina: Editora da UEL., 1999.

BRASIL. Portaria ${ }^{0}$ 393, de 15 de maio de 1998. Estabelece o métodos para determinação da biodegradabilidade de tensoativos aniônicos com validade em todo Território Nacional. Revoga a Portaria SVs n 120,de 24 de novembro de 1995, e dá outras providências. Diário Oficial [da] República Federativa do Brasil, Brasília, DF, Seção I, n. 93-E, p.1, 19 maio 1998. .
FAIRBANKS, M. Detergentes espera LAB para crescer. Química e Derivados, São Paulo, v.24, n.264, p.40-46.jul, 1989

MARTINS, A. Domissanitários: uma monografia didática. 1998. Monografia (Especialização em Química para Professores do Ensino Médio)Universidade Estadual de Londrina, Londrina, 1998.

MENEZES, L.C. Novos parâmetros curriculares para o ensino médio. São Paulo: [s.n.], 1998.

NOVAK, J.D.; GOWIN, D. B. Aprender a aprender. 2.ed. Lisboa: Plátamo, 1999. (Coleção Plátamo universitária).

SHREVE,R.N.; BRINK, S.A Indústria de Processos Químicos. 4.ed. Rio de Janeiro: Guanabara Koogan, 1997. 
